\title{
PENGARUH PENGgUNAAN AIR KOLAM TERHADAP KUAT TEKAN BETON (Studi Kasus Kecamatan. Kateman, Keritang dan Tembilahan Kota)
}

\author{
Muhammad Juldin ${ }^{1}$, Akbar Alfa ${ }^{2}$ \\ 1,2Prodi Teknik Sipil, Fakultas Teknik dan Ilmu Komputer, Universitas Islam Indragiri, Tembilahan \\ Email: muhammadjuldin@gmail.com (korespondensi)
}

\begin{abstract}
Concrete is a composite material (mixture) consisting of cement, coarse aggregates, fine aggregates and water. The concrete formation mixture is designed in such a way as to produce fresh concrete that is easy to work with and meets the plan's compressive strength after hardening.

The cement used is PCC type cement, although the composition of cement in concrete is only about $10 \%$, but the role of cement is very important in concrete. Aggregates are mineral granules originating from nature or artificial which have a function as a mixture of fillers in concrete. The aggregate of the concrete mixture filler is divided into fine aggregates used from Javanese Inhu and coarse aggregates from Tanjung Balai Karimun. The fine aggregate is usually in the form of sand that passes through a filter with a diameter of $4.75 \mathrm{~mm}$ or $5 \mathrm{~mm}$, while coarse aggregates do not pass through the filter. The water used is well water from Kateman District, Keritang District and Tembilahan District, Indragiri Hilir Regency, Riau Province.

The compressive strength of concrete is the amount of load per unit area which causes the concrete specimen to break and there is no more carrying capacity. The average compressive strength of 28 days of cube specimens with well water in Kateman District $=491 \mathrm{~kg} / \mathrm{cm} 2$, Keritang District $=469 \mathrm{~kg} / \mathrm{cm} 2$ and Tembilahan District City $=475 \mathrm{~kg} / \mathrm{cm} 2$. .
\end{abstract}

Keywords: Cement, Fine and Coarse Aggregate, Water, compressive strength.

\begin{abstract}
Abstrak
Beton merupakan bahan komposit (campuran) yang terdiri dari semen, agregat kasar, agregat halus dan air. Campuran bahan-bahan pembentukan beton dirancang sedemikian rupa, sehingga menghasilkan beton segar yang mudah dikerjakan dan memenuhi kekuatan tekan rencana setelah mengeras.
\end{abstract}

Semen yang digunakan adalah semen tipe PCC, walaupun komposisi semen dalam beton hanya sekitar $10 \%$, namun peran semen sangat penting dalam beton. Agregat adalah butiran mineral yang berasal dari alam atau buatan yang memiliki fungsi sebagai bahan pengisi campuran pada beton. Agregat pengisi campuran beton terbagi atas agregat halus yang digunakan berasal dari Japura Inhu dan agregat kasar berasal dari Tanjung Balai Karimun. Agregat halus biasanya berupa pasir yang lolos saringan dengan diameter 4,75 $\mathrm{mm}$ atau 5 $\mathrm{mm}$, sedangkan agregat kasar tidak lolos saringan tersebut. Air yang digunakan yakni air sumur berasal dari Kecamatan Kateman, Kecamatan Keritang dan Kecamatan Tembilahan Kota Kabupaten Indragiri Hilir Provinsi Riau.

Kuat tekan beton adalah besarnya beban per satuan luas yang menyebabkan benda uji beton pecah dan tidak ada lagi daya dukungnya. Hasil kuat tekan rata-rata umur 28 hari benda uji kubus dengan air sumur Kecamatan Kateman $=491 \mathrm{~kg} / \mathrm{cm} 2$, Kecamatan Keritang $=469$ $\mathrm{kg} / \mathrm{cm} 2$ dan Kecamatan Tembilahan Kota $=475 \mathrm{~kg} / \mathrm{cm} 2$.

Kata kunci: Semen, Agregat halus dan kasar, Air, Kuat tekan

\section{PENDAhUluan}

Beton merupakan bahan komposit (campuran) yang terdiri dari semen, agregat kasar, agregat halus dan air. Campuran bahan-bahan pembentukan beton dirancang sedemikian rupa, sehingga menghasilkan 
beton segar yang mudah dikerjakan dan memenuhi kekuatan tekan rencana setelah mengeras.

Air diperlukan pada pembuatan beton untuk memicu proses kimiawi semen, membasahi agregat halus, dan memberikan kemudahan dalam pekerjaan beton. Air yang digunakan untuk campuran beton harus bersih dan tidak boleh mengandung minyak yang dapat merusak beton. Air yang mengandung senyawa-senyawa berbahaya yang tercemar garam, minyak dan gula bila dipakai dalam campuran beton akan menurunkan kualitas beton, bahkan dapat mengubah sifat beton yang dihasilkan.

Beton banyak menjadi pilihan dan digunakan dalam konstruksi. Masyarakat di Indonesia dan khususnya Kabupaten Indragiri Hilir Provinsi Riau sebagian besar menggunakan beton untuk elemen struktur bangunan seperti rumah, kantor, dermaga, tanggul, jembatan, dam dan jalan.

Pengujian dilakukan terhadap beton yang terbentuk dari berbagai sumber air. Pengujian kuat tekan dilakukan untuk mengetahui pengaruh air yang digunakan terhadap kapasitas kuat tekan beton pada berbagai umur beton. Dari penelitian ini diharapkan dapat diketahui apakah air yang dipilih mempengaruhi kuat tekan beton atau tidak, sehingga dapat mengetahui jenis dan sumber air yang sesuai agar beton dapat mencapai kapasitas kuat tekan yang diharapkan.

\section{TINJAUAN PUSTAKA}

\subsection{Landasan Teori}

Beton adalah material komposit yang rumit, terdiri atas campuran material semen, air, agregat halus (pasir) dan agregat kasar (kerikil). Sifat beton sangat tergantung dari interaksi antar material pencampur. (Nugraha dan Antoni, 2007).

Beton normal diperoleh dengan cara mencampurkan semen Porland, air dan agregat, adapun untuk jenis beton khusus (selain beton normal) ditambahkan bahan tambah, misalnya pozolan, bahan kimia pembantu, serat dan sebagainya. Tujuan pemberian bahan tambah ialah untuk menghasilkan beton khusus yang lebih baik dari pada beton normal. macam-macam mutu serta jenis beton khusus telah berkembang sesuai dengan perkembangan jenis struktur dan jenis bangunan akhir-akhir ini, misalnya: beton untuk balok dan kolom harus beton yang kuat tekannya tinggi, beton yang selalu berhubungan dengan air atau untuk penahan air harus beton yang rapat air, beton yang selalu terendam air sulfat harus beton yang tahan sulfat, beton untuk elemennon-struktur yang digunakan beton ringan, dan sebagainya (Tjokrodimuljo, M.E, 2007). Beton dibandingkan dengan bahan bangunan lain mempunyai beberapa kelebihan, antara lain yaitu.

1. Harganya relatif murah.

2. Termasuk bahan yang awet, tahan aus, tahan kebakaran, tahan terhadap pengkaratan atau pembusukan oleh kondisi lingkungan, sehingga biaya perawatan murah.

3. Kuat tekannya cukup.

4. Beton segar dapat dengan mudah diangkut maupun dicetak dalam bentuk dan ukuran sesuai keinginan, Cetakan dapat dipakai beberapa kali.

Beton mempunyai kelebihan, namun beton juga mempunyai kekurangan, beberapa kekurangan itu antara lain.

1. Bahan dasar penyusun beton (agregat halus maupun agregat kasar) bermacam-macam sesuai dengan lokasi pengambilannya, sehingga cara perencanaan dan cara pembuatannya bermacam-macam pula.

2. Beton keras mempunyai beberapa kelas kekuatan sehingga harus disesuaikan dengan bagian bangunan yang dibuat, sehingga cara perencanaan dan cara pelaksanaannya bermacam-macam pula.

3. Beton mempunyai kuat tarik yang rendah, sehingga getas/rapuh dan mudah retak. Oleh karena itu perlu diberikan cara-cara mengatasinya, misalnya dengan memberikan baja tulangan, serat dan sebagainnya.

\subsection{Alat-alat Penelitian}

1. Ayakan dan Mesin Vibrator / Penggetar

2. Mesin Los Angeles

3. Molen (Concrete Mixer)

4. Cetakan Kubus Beton

5. Tamping Rod

6. Kerucut Abrams

7. Neraca atau Timbangan

8. Jangka Sorong (Sigmat/Vernier Caliper) dan Mistar

9. Gelas Ukur

10. Oven

11. Container atau Mould

12. Piknometer dan Mould

13. Mesin Uji Kuat Tekan

14. Timbangan dalam Air (Absorption of Coarse Aggregate Test Set)

\subsection{Material Campuran Beton}

Secara umum material beton yang digunakan pada konstruksi terdiri atas semen, air, pasir (agregat halus) dan kerikil atau batu pecah (agregat kasar) yang dicampur dengan perbandingan tertentu dan untuk menghasilkan kekuatan tertentu pula. 
Kekuatan yang diukur pun biasanya hanya kuat tekannya saja yang diuji pada umur 28 hari.

\subsubsection{Jenis-jenis Semen}

1. Semen Portland

2. Blanded Cemen (Semen Campur)

3. Semen Putih (White Cement)

4. Water Proofed Cemen

5. Oil Well Cement Class G-HSR (High Sulfate Resistance)

\subsubsection{Agregat}

Agregat adalah butiran mineral yang berasal dari alam atau buatan yang memiliki fungsi sebagai bahan pengisi campuran pada beton. Agregat pengisi campuran beton terbagi atas agregat halus dan agregat kasar. Agregat halus biasanya berupa pasir atau partikel-partikel lain yang lolos saringan dengan diameter $4,75 \mathrm{~mm}$ atau $5 \mathrm{~mm}$, sedangkan agregat kasar tidak lolos saringan tersebut, pada umumnya penggunaan bahan agregat dalam adukan beton yaitu agregat kasar dan agregat halus mencapai jumlah sekitar $70 \%-75 \%$ dari seluruh volume massa padat beton (Dipohusodo, 1994).

Menurut Amri (2005), kandungan agregat halus tidak boleh mengandung susunan butiran yang tidak mampu mengisi rongga-rongga yang ada di antara agregat kasar. Campuran yang kekurangan agregat halus sukar untuk dikerjakan dan pada saat pengecoran akan membentuk kantongkantong udara, dalam keadaan sebaliknya dimana agregat halus lebih banyak dibandingkan dengan agregat kasar akan menghasilkan beton dengan permukaan yang kasar dan dibutuhkan lebih banyak air agar diperoleh faktor kemudahan kerja.

Tabel 1 Persyaratan yang di Izinkan untuk Agregat

\begin{tabular}{|c|c|c|}
\hline \multirow{2}{*}{$\begin{array}{l}\text { Macam } \\
\text { Pemeriksaan }\end{array}$} & \multicolumn{2}{|c|}{ Persyaratan } \\
\hline & $\begin{array}{l}\text { Agregat } \\
\text { Halus }\end{array}$ & $\begin{array}{l}\text { Agregat } \\
\text { Kasar }\end{array}$ \\
\hline $\begin{array}{ll}\text { Kadar } & \text { lumpur, } \\
\text { maksimal } & \end{array}$ & $3 \%$ & $5 \%$ \\
\hline $\begin{array}{l}\text { Lewat saringan No. } \\
\text { 200, maksimal }\end{array}$ & $5 \%$ & $1 \%$ \\
\hline Kotoran organik & No. 3 & - \\
\hline $\begin{array}{ll}\text { Partikel } & \text { lunak, } \\
\text { maksimal } & \end{array}$ & $1 \%$ & $1 \%$ \\
\hline $\begin{array}{l}\text { Pertikel ringan, } \\
\text { maksimal }\end{array}$ & $1 \%$ & $1 \%$ \\
\hline Berat jenis, minimum & 2,3 & 2,3 \\
\hline $\begin{array}{l}\text { Peresapan, } \\
\text { maksimum }\end{array}$ & $5 \%$ & $5 \%$ \\
\hline Berat isi, minimum & $1 / 2 \mathrm{~kg} / \mathrm{l}$ & $1 / 2 \mathrm{~kg} / \mathrm{l}$ \\
\hline $\begin{array}{l}\text { Kehausan } \quad \text { (Los } \\
\text { Angeles), maksimum }\end{array}$ & - & $40 \%$ \\
\hline $\begin{array}{l}\text { Soundness } \\
\text { - Na2SO4, }\end{array}$ & $10 \%$ & $12 \%$ \\
\hline
\end{tabular}

\begin{tabular}{|l|l|l|}
\hline \multirow{2}{*}{$\begin{array}{l}\text { Macam } \\
\text { Pemeriksaan }\end{array}$} & \multicolumn{2}{|l|}{ Persyaratan } \\
\cline { 2 - 3 } & $\begin{array}{l}\text { Agregat } \\
\text { Halus }\end{array}$ & $\begin{array}{l}\text { Agregat } \\
\text { Kasar }\end{array}$ \\
\hline $\begin{array}{c}\text { maksimum } \\
\text { NaSO4, } \\
\text { maksimum }\end{array}$ & $15 \%$ & $18 \%$ \\
\hline $\begin{array}{l}\text { Impak value, } \\
\text { maksimum }\end{array}$ & - & $30 \%$ \\
\hline Crushing value & - & $30 \%$ \\
\hline
\end{tabular}

Sumber: Departemen Pekerjaan Umum Direktorat Jendral Bina Marga

\section{Agregat Kasar}

a. Butirannya keras dan tidak berpori. Indeks kekerasan $\leq 5 \%$ (diuji dengan goresan batang tembaga). Bila diuji dengan bejana rudellof atau los Angeles.

b. Kekal atau tidak pecah atau hancur oleh pengaruh cuaca (terik matahari dan hujan). Jika diuji dengan larutan garam natrium sulfat bagian yang hancur maksimal $12 \%$, jika dengan garam magnesium sulfat maksimum $18 \%$.

c. Tidak mengandung lumpur (butiran halus yang lewat ayakan 0,06 $\mathrm{mm}$ ) lebih $1 \%$.

d. Butiran agregat yang pipih dan lonjong tidak boleh lebih dari $20 \%$.

e. Modulus halus butir antara $6-7,10$ dan variasi butir yang sesuai standar gradasi.

f. Ukuran butir maksimum tidak boleh melebihi dari : $1 / 5$ jarak terkecil antara bidang-bidang cetakan, 1/3 tebal pelat beton, $3 / 4$ jarak bersih antar tulangan.

\section{Agregat Halus}

a. Butir-butirnya tajam, dan keras dengan indeks kekerasan $\leq 2,2$.

b. Kekal, tidak mudah pecah atau hancur oleh pengaruh cuaca (terik matahari dan hujan). Jika diuji dengan larutan garam natrium sulfat bagian yang hancur maksimal $12 \%$, jika dengan garam magnesium sulfat maksimum $18 \%$.

c. Tidak mengandung lumpur (butiran halus yang lewat ayakan 0,06 mm) lebih $5 \%$.

d. Tidak mengandung zat organik yang terlalu banyak, yang dibuktikan dengan larutan $3 \% \mathrm{NaOH}$, yaitu warna cairan diatas endapan diatas agregat halus tidak boleh lebih gelap dari pada warna standar pembanding.

e. Modulus halus butir memenuhi antara 1,50 - 3,80 dan sesuai dengan variasi butir sesuai standar gradasi.

f. Khusus untuk beton untuk tingkat keawetan tinggi, agregat halus harus tidak reaktif terhadap alkhali. 


\section{Air}

Air yang dapat diminum dapat digunakan untuk campuran beton, namun demikian air yang tak dapat diminum pun dapat digunakan sebagai campuran beton, asalkan memenuhi syarat mutu yang disyaratkan. Air yang digunakan untuk campuran beton harus bersih, tidak boleh mengandung minyak, asam, alkali, zat organis atau bahan lainnya yang dapat merusak beton atau tulangan (Mulyono, 2004).

\subsection{Pekerjaan Beton}

\subsubsection{Perencanaan Design)}

Tujuan utama mempelajari sifatsifat beton adalah untuk perencanaan campuran (Mix Design), yaitu pemilihan dari bahan-bahan beton yang memadai, serta menentukan proporsi masing-masing bahan untuk menghasilkan beton yang ekonomis dengan kualiatas yang baik (Nugraha dan Antoni, 2007).

\subsubsection{Percobaan Pendahuluan (Trial Mixing)}

Setelah melakukan perencanaan adukan harus dikontrol dengan uji coba dan percobaan pendahuluan, yaitu membuat campuran percobaan (trial mixes) seperti komposisi yang telah didapatkan dalam mix desain untuk memastikan hasilnya, apakah campuran benar-benar mencapai kekuatan yang direncanakan (Samekto dan Rahmadiyanto, 2001).

\subsubsection{Pengolahan Beton}

Pengolahan beton adalah proses pembuatan beton dari pencampuran bahanbahan beton, pengangkutan adukan beton, pemadatan, perataan permukaan beton dan perawatan selama proses pengerasan beton (Tjokrodimuljo, 2007).

\subsubsection{Pengendalian Pekerjaan Beton}

Kekuatan beton yang diproduksi di lapangan mempunyai kecenderungan untuk bervariasi. Atas adanya variasi kekuatan tekan beton tersebut maka diperlukan adanya pengendalian terhadap mutu (quality control) untuk memperoleh kekuatan tekan yang hampir seragam dan memenuhi Rencana Kerja dan Syarat (Tjokrodimuljo, 2007). Selama masa pelaksanaan pengendalian mutu dilakukan dengan memantau dan mengevaluasi secara terusmenerus agar beton sesuai dengan yang direncanakan sebelumnya.

\subsection{Kuat Tekan Beton}

Kuat tekan beton adalah besarnya beban per satuan luas yang menyebabkan benda uji beton pecah dan tidak ada lagi daya dukungnya, yang dihasilkan oleh mesin tekan. Kekuatan tekan beton ditentukan oleh pengaturan dari perbandingan semen, agregat kasar, agregat halus dan air. Secara umum bahwa kuat tekan beton, akan meningkat dengan pertambahan umurnya. Waktu toleransi yang diijinkan untuk memperoleh kuat tekan beton pada berbagai umur sebagai berikut.

\subsection{Umur Beton}

Kekuatan beton akan bertambah dengan naiknya umur beton. Kekuatan beton akan naik secara cepat (linier) sampai umur 28 hari, tetapi setelah itu kenaikannya akan kecil. Kekuatan tekan beton pada kasus tertentu akan bertambah sampai beberapa tahun, biasanya kekuatan tekan rencana beton dihitung pada umur 28 hari (Mulyono, 2004).

Perawatan beton yang baik membantu meningkatkan kualitas beton. Kontrol yang baik terhadap temperatur udara, kecepatan angin, suhu beton dan tingkat kelembaban relatif akan meningkatkan kualitas beton seiring dengan bertambahnya umur beton (Dill dalam Newman dan Choo, 2003).

\section{METODOLOGI PENELITIAN}

\subsection{Bagan Alir Penelitian}

Penelitian ini bertujuan untuk membandingkan dan mengetahui pangaruh penggunaan jenis air kolam terhadap kuat tekan beton. air kolam yang digunakan berasal dari Kecamatan Kateman, Kecamatan Keritang dan Kecamatan Tembilahan Kota, Kabupaten Indragiri Hilir Provinsi Riau, ke dalam campuran semen, agregat halus dan agregat kasar, semua sampel di uji pada umur yang telah ditentukan untuk melihat perkembangan kuat tekan dari masing-masing sampel. Pengujian tes tekan beton menggunakan 27 sampel beton. Benda uji yang dicetak pada penelitian ini dicetak dengan menggunakan cetakan kubus dengan ukuran $150 \times 150 \times 150 \mathrm{~mm}$. Kubus beton tersebut dirawat dengan direndam di dalam air bersih dan kemudian diuji pada umur 3, 7 dan 28 hari. 


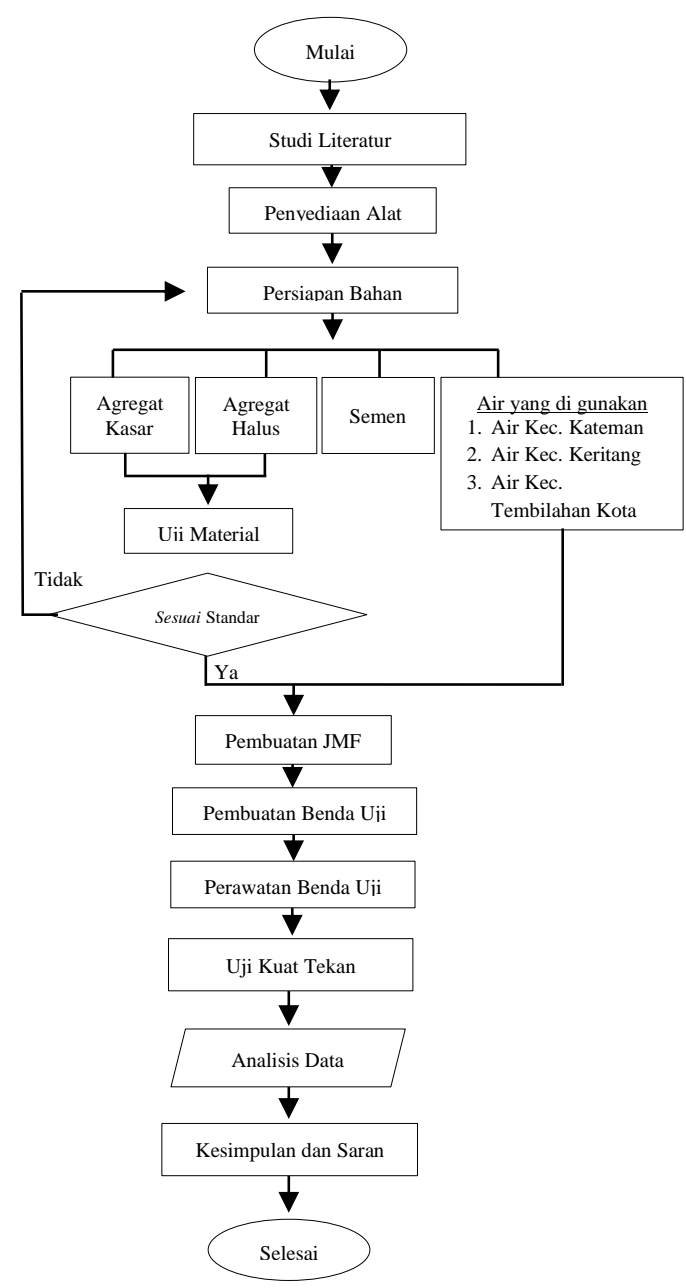

Gambar.1 Bagan Alir Penelitian (Flow Chart) Sumber: Data Olahan

\subsection{Prosedur Penelitian}

\subsubsection{Tempat dan Waktu Penelitian}

Tempat pembuatan benda uji, pemeliharaan, dan pengujian dilaksanakan di Laboratorium Dinas Pekerjaan Umum dan Penataan Ruang (PUPR) Kabupaten Indragiri Hilir. Penelitian dilakukan selama 6 bulan yaitu mulai bulan November 2018 sampai dengan bulan April 2019.

\subsubsection{Persiapan Alat}

1. Ayakan

Ayakan digunakan untuk mengetahui gradasi agregat kasar dan agregat halus yang digunakan dalam penelitian. Ukuran ayakan maksimal yang digunakan untuk agregat kasar adalah ayakan diameter 1 inci $(25,4 \mathrm{~mm})$ sampai no. $4(4,75 \mathrm{~mm})$, sedangkan untuk agregat halus memiliki ukuran ayakan maksimal No.4 (4.75 mm) sampai no. $200(0,075 \mathrm{~mm})$.

2. Mesin Los Angeles
Mesin los angeles digunakan untuk menguji keausan agregat kasar. Agregat kasar diuji dengan mesin los angeles sebanyak 500 atau 1000 kali putaran dengan dimasukkan 11 atau 12 bola baja tergantung ukuran batu pecah yang mau diteliti, cara ini menentukan apakah agregat kasar tersebut layak atau tidak digunakan.

3. Molen (Concrete Mixer)

Alat ini berfungsi untuk mengaduk bahan penyusun beton sehingga diperoleh campuran yang homogen. Alat ini mampu membuat adukan segar untuk 9 buah Silinder beton. Molen ini digerakkan dengan dinamo listrik.

4. Cetakan Kubus Beton

Alat ini berfungsi untuk mencetak sample beton berbentuk kubus. alat ini dibuat dari baja yang terdiri dari empat keping plat baja berbentuk persegi. Plat disatukan dengan menggunakan baut dan bagian bawah juga menggunakan plat berbentuk persegi. Cetakan kubus dengan ukuran $150 \times 150 \times 150 \mathrm{~mm}$.

5. Tamping Rod

Tamping Rod ini berupa batangan besi yang memiliki panjang sekitar $600 \mathrm{~mm}$. Alat ini digunakan dengan cara ditumbukkan kedalam cetakan saat pelaksanaan berat isi dan pengecoran. Pemadatan dilakukan sebanyak 25 kali tusukan setiap $1 / 3$ bagian kubus / silinder terisi dengan adukan.

6. Kerucut Abrams

Alat ini berfungsi untuk mengukur nilai slump beton segar. Memiliki ukuran diameter bagian atas $100 \mathrm{~mm}$, diameter bagian bawah $200 \mathrm{~mm}$ dan memiliki tinggi $300 \mathrm{~mm}$.

7. Neraca atau Timbangan

Neraca digunakan untuk menimbang benda uji yang diteliti dalam laboratorium. Selain itu neraca juga digunakan untuk menimbang bahan yang akan digunakan sebagai campuran beton. Neraca yang dipakai ada 4 macam yang memiliki ketelitian masing- masing $0.01 \mathrm{gr}, 0,1 \mathrm{gr}$ dan $1 \mathrm{gr}$.

8. Jangka Sorong (Sigmat/Vernier Caliper) dan Mistar

Mistar dan jangka sorong (Sigmat/Vernier Caliper) digunakan untuk mengukur benda uji, penurunan nilai slump dan pengukuran kubus beton.

9. Gelas Ukur

Gelas ukur digunakan untuk untuk menakar jumlah air yang digunakan dalam pembuatan beton.

10. Oven 
Oven digunakan untuk mengeringkan agregat sehingga bisa dihitung kadar air yang terkandung dalam agregat yang digunakan.

11. Container atau Mool

Alat penakar berbentuk silinder terbuat dari logam atau bahan kedap air dengan ujung dan dasar yang benar-benar rata, dengan kapasitas berbeda sesuai dengan kegunaan.

12. Piknometer dan Mould

Alat ini digunakan untuk menentukan berat jenis (bulk), berat jenis kering permukaan jenuh SSD (Satureted Surface Dry).

13. Mesin Uji Kuat Tekan

Alat ini digunakan untuk mengukur nilai kuat tekan yang dimiliki oleh beton. Alat yang digunakan dalam penelitian ini memiliki kemampuan untuk menekan sampai $2000 \mathrm{kN}$.

14. Timbangan dalam Air (Absorption Of Coarse Aggregate Test Set)

Alat ini digunakan untuk menimbang agregat kasar di dalam air yang dilengkapi dengan timbangan khusus agar dapat mengetahui berat benda uji didalam air.

\subsubsection{Persiapan Bahan}

\section{Agregat Kasar (Split)}

Agregat kasar yang digunakan adalah batu pecah (split) berasal dari Tanjung Balai Karimun. agregat kasar memiliki partikel lebih besar dari pada $4,75 \mathrm{~mm}$, harus berbutir keras dan tidak berpori, tidak boleh mengandung lumpur lebih dari $1 \%$ dari berat kering, butirannya harus bervariasi, tajam, kuat dan bersudut.

2. Agregat Halus (Pasir)

Agregat halus yang digunakan adalah pasir yang diambil dari Japura (Inhu). pasir yang berfungsi sebagai bahan pengisi, harus bebas dari bahan organic dan lempung, tersaring dalam ukuran no.4-100, gradasi berukuran $n<100$ dapat merusak campuran beton, tidak boleh mengandung lumpur lebih dari 5\% terhadap berat kering.

3. Semen

Semen yang digunakan PCC sesuai standar SNI (15-7064-2004) dengan kemasan kantong $50 \mathrm{~kg}$, kemasan dalam keadaan tertutup dan tidak terdapat kerusakan pada segel maupun pembungkus.

4. Air

Air yang digunakan ialah air kolam yang berasal dari Kecamatan Kateman, Kecamatan Keritang, dan Kecamatan
Tembilahan Kota. Kabupaten Indragiri Hilir Provinsi Riau. tujuan utama dari penggunaan air adalah agar terjadi hidrasi, yaitu reaksi kimia yang terjadi antara semen dan air yang menyebabkan campuran menjadi lecak dan keras setelah lewat beberapa waktu.

\subsubsection{Pembuatan Job Mix Formula (JMF)}

1. Pengujian Agregat Kasar

a. Uji Keausan Agregat Kasar

b. Analisa Saringan Agregat Kasar

c. Pengujian Kadar Air Agregat Kasar

d. Pengujian Berat Isi Agregat Kasar

e. Pengujian Berat Jenis Agregat Kasar

2. Pengujian Agregat Halus

a. Analisa Saringan Agregat Halus

b. Pengujian Kadar Air Agregat Halus

c. Pengujian Berat Isi Agregat Halus

d. Pengujian Berat Jenis Agregat Halus

e. Pengujian Kadar Zat Organik Agregat Halus

3. Perencanaan Campuran (Mix Design)

a. Menentukan kuat tekan beton yang disyaratkan pada umur 28 hari benda uji berbentuk kubus, kuat tekan karakteristik ... kg/cm2, untuk umur beton 28 hari bagian tak memenuhi syarat $5 \%(k=1,64)$.

b. Menentukan nilai deviasi standar (S) agregat berdasarkan volume, semen ditimbang, kontrol pekerjaan, pengawasan bisa dilapangan, presentase kekuatan tekan diatas harga minimum $95 \%$ tingkat pengawasan sedang 70 .

c. Menentukan nilai tambah $\mathrm{M}=1,64 \mathrm{x}$ Standar Deviasi.

d. Menentukan kekuatan rata-rata yang hendak dicapai adalah kuat tekan yang disyaratkan + nilai tambah.

e. Menentukan jenis semen, dalam pengujian ini semen yang digunakan adalah Portland Composite Cement (PCC) yang penggunaannya tidak memakai persyaratan khusus, jadi sama seperti semen tipe 1 .

f. Menentukan jenis agregat yang digunakan, untuk halus yang digunakan yaitu alami, menggunakan pasir Japura (Inhu) dan agregat kasar yang digunakan yaitu batu pecah tanjung balai.

g. Menentukan faktor air semen (FAS) bebas.

h. Menentukan faktor air semen (FAS) maksimum.

i. Menentukan nilai slump.

j. Menentukan jenis agregat kasar yakni batu pecah/split ukuran 
maksimal agregat.

k. Menentukan kadar air bebas.

I. Menentukan jumlah semen.

m. Menentukan susunan gradasi atau jenis agregat.

n. Menetukan nilai persen agregat halus.

o. Menentukan nilai berat jenis relatif agregat kasar dan halus (kondisi kering permukaan / SSD).

p. Menentukan berat isi beton.

q. Mementukan kadar agregat gabungan.

r. Menentukan kadar agregat halus.

s. Menentukan kadar agregat kasar.

t. Menentukan proporsi campuran (semen, agregat halus, agregat kasar dan air).

u. Menentukan perbandiangan semen : agregat gabungan.

4. Pengadukan Material Campuran Beton

a. Mencuci isi dalam molen dengan air.

b. Memasukkan agregat kasar (split) ke dalam molen.

c. Menambahkan atau mencampurkan agregat halus hingga merata ke dalam mesin pengaduk campuran beton (molen).

d. Menambahkan semen ke dalam adukan.

e. Menambahkan air secara bertahap sesuai kebutuhan.

5. Pencetakan Benda Uji

a. Mempersiapkan cetakan kubus dan adukan.

b. Memberikan pelumas pada permukaan dinding bagian dalam dan alas bagian dalam cetakan.

c. Mengisi adukan beton ke dalam cetakan, selanjutnya dilakukan pemadatan adukan dengan menusukan besi pemadat sebanyak 25 tusukan pada setiap lapisan adukan dengan tebal $1 / 3$ tinggi cetakan (terdapat 3 lapisan).

d. Meratakan permukaan bagian atas beton.

e. Memberi nama atau kode pada beton sebelum mengeras.

f. Membongkar cetakan setelah umur beton 24 jam.

6. Perawatan Benda Uji

Perawatan benda uji yang dilakukan sesuai dengan SNI-03-2493-1991. Perawatan dilakukan setelah pembongkaran cetakan lalu direndam di dalam air bersih sesuai dengan umur beton yang di rencanakan. Benda uji dikeluarkan dari bak perendam sehari sebelum pengujian tekan dilakukan. Kebutuhan air yang digunakan untuk merendam benda uji selalu dikontrol agar air perendam beton tidak mengalami kekurangan selama proses perawatan.

7. Pengujian Kuat Tekan

Tahap pengujian kuat tekan beton dilaksanakan setelah tahapan perawatan benda uji. Pengujian dilakukan ketika benda uji beton berumur 3, 7 dan 28 hari. Pengujian kuat tekan beton dilaksanakan berdasarkan SK SNI 03-1974-1990. Pengujian kuat tekan beton dilaksanakan untuk mengetahui seberapa besar kapasitas beton mampu menahan kuat tekan maksimum. Pengujian kuat tekan beton dilakukan dengan mengeluarkan benda uji dari bak perendam.

a. Benda uji yang telah dikeluarkan dari bak perendam diangin-anginkan selama waktu yang sudah ditentukan pada Tabel. 2.17 Waktu Toleransi diijinkan.

b. Penimbang dan Pengukuran dimensi benda uji.

c. Pengujian kuat tekan beton menggunakan alat uji tekan UTM (Universal Testing Machine) dengan kapasitas alat sebesar 2000 kN.

d. Data yang diperoleh dari pengujian adalah data beban maksimum yang mampu ditahan oleh benda uji.

\section{HASIL DAN PEMBAHASAN}

\subsection{Analisa}

Sebelum pembuatan benda uji, terlebih dahulu dilakukan pengujian terhadap bahanbahan. Data-data hasil pengujian akan disusun mulai dari pengujian bahan hingga pengujian akhir benda uji, dari hasil pengujian tersebut akan dilanjutkan dengan analisis mengenai hasil pengujian tersebut.

\subsubsection{Pengujian Bahan}

1. Pengujian Agregat Kasar a. Uji Keausan Agregat Kasar

\begin{tabular}{|c|c|c|c|}
\hline \multicolumn{2}{|c|}{ Gradasi Pemeriksaan } & $\begin{array}{c}\text { Jumlah Putaran = 500 } \\
\text { Putaran }\end{array}$ \\
\hline \multicolumn{2}{|c|}{ Ukuran Saringan } & I & II \\
\hline Lolos & $\begin{array}{c}\text { Tertah } \\
\text { an }\end{array}$ & Berat (a) & Berat (b) \\
\hline $76,2\left(3^{\prime \prime}\right)$ & $\begin{array}{c}63,5(21 / 2 \\
\text { ") }\end{array}$ & & \\
\hline $63,5\left(21 / 2^{\prime \prime}\right)$ & $50,8\left(2^{\prime \prime}\right)$ & & \\
\hline $50,8\left(2^{\prime \prime}\right)$ & $\begin{array}{c}36,1(1) \\
\text { ") }\end{array}$ & & 1250 \\
\hline $36,1\left(11^{\prime \prime}\right)$ & $25,4\left(1^{\prime \prime}\right)$ & 1250 & 1250 \\
\hline $25,4\left(1^{\prime \prime}\right)$ & $19,1\left(3 / 4^{\prime \prime}\right)$ & 1250 & 1250 \\
\hline $19,1\left(3 / 4^{\prime \prime}\right)$ & $12,7\left(1 / 2^{\prime \prime}\right)$ & 1250 & \\
\hline $12,7\left(1 / 2^{\prime \prime}\right)$ & $9,52(3 / 8)$ & 1250 & \\
\hline $9,52\left(3 / 8^{\prime \prime}\right)$ & $6,35\left(1 / 4^{\prime \prime}\right)$ & & \\
\hline $6,35\left(1 / 4^{\prime \prime}\right)$ & $\begin{array}{c}4,75(\text { No. } \\
4)\end{array}$ & & \\
\hline $4,75($ No. 4$)$ & $2,36($ No. & & \\
\hline \multicolumn{2}{|c|}{ Jumlah Berat } & 5000 & \\
\hline
\end{tabular}




\begin{tabular}{|c|c|c|}
\hline Berat Tertahan Saringan No. & 3650 & 3640 \\
\hline
\end{tabular}

I. Kehausan $=\frac{a-b}{a} \times 100 \%=29,90$

II. Kehausan $=\frac{a-b}{a} \times 100 \%=30,00$

Kehausan rata-rata $=29,95$

\section{b. Analisa Saringan Agregat Kasar}

\begin{tabular}{|c|c|c|c|c|}
\hline \multirow{2}{*}{ Saringan } & \multirow{2}{*}{$\begin{array}{c}\text { Berat } \\
\text { Tertahan }\end{array}$} & \multirow{2}{*}{$\begin{array}{l}\text { Jumlah } \\
\text { Berat } \\
\text { Tertahan }\end{array}$} & \multicolumn{2}{|c|}{ Jumlah Persen } \\
\hline & & & $\%$ Tertahan & $\%$ Lewat \\
\hline \multicolumn{5}{|l|}{$76,2(3 ")$} \\
\hline \multicolumn{5}{|l|}{$63,5(21 / 2 ")$} \\
\hline \multicolumn{5}{|l|}{$50,8(2 ")$} \\
\hline $36,1(11 / 2 ")$ & 0,00 & 0,00 & 0,00 & 100,00 \\
\hline \multicolumn{5}{|l|}{$25,4\left(1^{\prime \prime}\right)$} \\
\hline $\begin{array}{c}19,1\left(3 / 4^{\prime \prime}\right. \\
\text { ( }\end{array}$ & 3740 & 3740 & 34,92 & 65,08 \\
\hline \multicolumn{5}{|l|}{$\begin{array}{c}12,7(1 / 2 \\
\text { ") }\end{array}$} \\
\hline $9,52\left(3 / 8^{\prime \prime}\right)$ & 5540 & 9280 & 86,65 & 13,35 \\
\hline No. 4 & 820 & 10100 & 94,30 & 5,70 \\
\hline No. 8 & 155 & 10255 & 95,75 & 4,25 \\
\hline \multicolumn{5}{|l|}{ No. 10} \\
\hline No. 16 & 85 & 10340 & 96,55 & 3,45 \\
\hline No. 30 & 55 & 10395 & 97,06 & 2,94 \\
\hline \multicolumn{5}{|l|}{ No. 40} \\
\hline No. 50 & 50 & 10445 & 97,53 & 2,47 \\
\hline No. 100 & 85 & 10530 & 98,32 & 1,68 \\
\hline No. 200 & 125 & 10655 & 99,49 & 0,51 \\
\hline Pan & 55 & 10710 & 100,00 & 0,00 \\
\hline
\end{tabular}

\begin{tabular}{|c|c|c|c|c|}
\hline \multirow{2}{*}{$\begin{array}{c}\text { Berat } \\
\text { Tertahan }\end{array}$} & \multirow{2}{*}{$\begin{array}{c}\text { Jumlah } \\
\text { Berat } \\
\text { Tertahan }\end{array}$} & \multicolumn{2}{|c|}{ Rata Rata } & \multirow{2}{*}{$\begin{array}{l}\text { Rata } \\
\text { Rata }\end{array}$} \\
\hline & & $\%$ Lewat & $\%$ Lewat & \\
\hline & & & & \\
\hline 0 & 0 & 0.00 & 100,00 & 100,00 \\
\hline 3725 & 3725 & 34,79 & 65,21 & 65,15 \\
\hline & & & & \\
\hline$\frac{5560}{840}$ & $\begin{array}{c}9285 \\
10125\end{array}$ & $\begin{array}{l}80,11 \\
94,56\end{array}$ & $\frac{13,29}{5,44}$ & $\frac{13,32}{5,57}$ \\
\hline 35 & 10260 & 95,82 & 4,18 & 4,22 \\
\hline 89 & 10349 & 96,65 & 3,35 & 3,40 \\
\hline 52 & 10401 & 97,13 & 2,87 & 2,90 \\
\hline 55 & 10456 & 97,65 & 2,35 & 2,41 \\
\hline 81 & 10537 & 98,40 & 1,60 & 1,64 \\
\hline 120 & 10657 & 99,52 & 0,48 & 0,49 \\
\hline 51 & 10708 & 100,00 & 0,00 & 0,00 \\
\hline \multicolumn{4}{|c|}{ Kehalusan } & 6,45 \\
\hline
\end{tabular}

\section{Pengujian Kadar Air Agregat Kasar}

\begin{tabular}{|l|c|c|c|}
\hline \multirow{2}{*}{ Pengujian } & \multirow{2}{*}{ Notasi } & \multicolumn{2}{c|}{ Sampel } \\
\cline { 3 - 4 } & & I & II \\
\hline Berat Talam & W1 & 56,91 & 55,73 \\
\hline $\begin{array}{l}\text { Berat Talam + Benda } \\
\text { Uji Basah }\end{array}$ & W2 & 157,35 & 156,93 \\
\hline $\begin{array}{l}\text { Berat Talam + Benda } \\
\text { Uji Kering }\end{array}$ & W3 & 156,50 & 156,09 \\
\hline Berat Air & $\begin{array}{c}\text { W4 =W2- } \\
\text { W3 }\end{array}$ & 0,85 & 0,84 \\
\hline Berat Uji kering & $\begin{array}{c}\text { W5 W W }- \\
\text { W1 }\end{array}$ & 99,59 & 100,36 \\
\hline Kadar Air & $\begin{array}{c}\text { W4/W5 } x \\
100\end{array}$ & 0,85 & 0,84 \\
\hline Kadar Air Rata-rata & \multicolumn{3}{|c|}{0,84} \\
\hline
\end{tabular}

\section{d. Pengujian Berat Isi Agregat Kasar}

\begin{tabular}{|l|c|c|c|}
\hline \multirow{2}{*}{ Lepas / Gembur } & \multirow{2}{*}{ Notasi } & \multicolumn{2}{|c|}{ Sampel } \\
\cline { 3 - 4 } & & I & II \\
\hline Berat Tempat + Benda Uji & $\mathrm{A}$ & 19.570 & 19.550 \\
\hline Berat Tepat & $\mathrm{B}$ & 5.115 & 5.115 \\
\hline Berat Benda Uji & $\mathrm{C}$ & 14.455 & 14.435 \\
\hline Volume Tempat & $\mathrm{D}$ & 10.090 & 10.090 \\
\hline
\end{tabular}

\begin{tabular}{|l|c|c|c|}
\hline Berat Isi Benda Uji & C / D & 1,43 & 1,43 \\
\hline Berat Isi Rata-rata & \multicolumn{3}{|c|}{1,43} \\
\hline
\end{tabular}

Sumber : Hasil Pengujian Labor

\begin{tabular}{|l|c|c|c|}
\hline \multirow{2}{*}{ Padat } & \multirow{2}{*}{ Notasi } & \multicolumn{2}{c|}{ Sampel } \\
\cline { 3 - 4 } & & I & II \\
\hline Berat Tempat + Benda Uji & $\mathrm{A}$ & 20.900 & 21.000 \\
\hline Berat Tepat & $\mathrm{B}$ & 5.115 & 5.115 \\
\hline Berat Benda Uji & $\mathrm{C}$ & 15.785 & 15.885 \\
\hline Volume Tempat & $\mathrm{D}$ & 10.090 & 10.090 \\
\hline Berat Isi Benda Uji & $\mathrm{C} / \mathrm{D}$ & 1,56 & 1,57 \\
\hline Berat Isi Rata-rata & \multicolumn{4}{|l}{} \\
\hline
\end{tabular}

e. Pengujian Berat Jenis Agregat Kasar

\begin{tabular}{|c|c|c|c|c|c|}
\hline \multirow{2}{*}{\multicolumn{2}{|c|}{ Pengujian }} & \multirow{2}{*}{ Notasi } & \multicolumn{3}{|c|}{ Sampel } \\
\hline & & & \multicolumn{2}{|c|}{ I } & II \\
\hline Berat Contoh JKP/SSD & A & gram & & 00 & 5000 \\
\hline Berat Dalam Air & $\mathrm{B}$ & gram & & 25 & 3022 \\
\hline Berat Contoh Kering Oven & C & gram & & 02 & 4901 \\
\hline \multirow{2}{*}{ Perhitungan } & \multirow{2}{*}{\multicolumn{2}{|c|}{ Notasi }} & \multicolumn{2}{|c|}{ Sampel } & Rata \\
\hline & & & $\mathbf{I}$ & II & rata \\
\hline $\begin{array}{l}\text { Berat Benda Uji Curah } \\
\text { Kering (Sd) }\end{array}$ & & & 2.48 & 2.48 & 2.48 \\
\hline $\begin{array}{l}\text { Berat Benda Uji Jenuh } \\
\text { Kering Permukaan (Ss) }\end{array}$ & & $\frac{A}{-A}$ & 2.53 & 2.53 & 2.53 \\
\hline Berat Jenis Semu (Sa) & & $\frac{\bar{c}}{-S}$ & 2.61 & 2.61 & 2.61 \\
\hline Penyerapan Air (Sw) & & $-x 100$ & 2.00 & 2.02 & 2.01 \\
\hline
\end{tabular}

2. Pengujian Agregat Halus

a. Analisa Saringan Agregat Halus

\begin{tabular}{|c|c|c|c|c|}
\hline \multirow{2}{*}{ Saringan } & \multirow{2}{*}{$\begin{array}{c}\text { Berat } \\
\text { Tertahan }\end{array}$} & \multirow{2}{*}{$\begin{array}{c}\text { Jumlah } \\
\text { Berat } \\
\text { Tertahan }\end{array}$} & \multicolumn{2}{|c|}{ Jumlah Persen } \\
\hline & & & $\%$ Tertahan & \% Lewat \\
\hline \multicolumn{5}{|l|}{$76,2(3$ ") } \\
\hline \multicolumn{5}{|l|}{$63,5(21 / 2 ")$} \\
\hline \multicolumn{5}{|l|}{50,8 ( 2 ") } \\
\hline \multirow{2}{*}{\multicolumn{5}{|c|}{$\frac{36,1(11 / 2 ")}{25,4\left(1^{\prime \prime}\right)}$}} \\
\hline & & & & \\
\hline \multicolumn{5}{|l|}{$\begin{array}{c}19,1\left(3 / 4^{\prime \prime}\right. \\
\text { ( }\end{array}$} \\
\hline \multicolumn{5}{|l|}{$\begin{array}{c}12,7(1 / 2 \\
")\end{array}$} \\
\hline $9,52\left(3 / 8^{\prime \prime}\right)$ & 0 & 0 & 0,00 & 100,00 \\
\hline No. 4 & 10 & 10 & 0,60 & 99,40 \\
\hline No. 8 & 190 & 200 & 12,03 & 87,97 \\
\hline \multicolumn{5}{|l|}{ No. 10} \\
\hline No. 16 & 560 & 760 & 45,70 & 54,30 \\
\hline No. 30 & 715 & 1475 & 88,70 & 11,30 \\
\hline \multicolumn{5}{|l|}{ No. 40} \\
\hline No. 50 & 125 & 1600 & 96,21 & 3,79 \\
\hline No. 100 & 10 & 1610 & 96,81 & 3,19 \\
\hline No. 200 & 50 & 1660 & 99,82 & 0,18 \\
\hline Pan & 3 & 1663 & 100,00 & 0,00 \\
\hline \multirow{2}{*}{$\begin{array}{c}\text { Berat } \\
\text { Tertahan }\end{array}$} & \multirow{2}{*}{$\begin{array}{c}\text { Jumlah } \\
\text { Berat } \\
\text { Tertahan }\end{array}$} & \multicolumn{2}{|c|}{ Rata Rata } & \multirow{2}{*}{$\begin{array}{l}\text { Rata } \\
\text { Rata }\end{array}$} \\
\hline & & $\%$ Lewat & $\%$ Lewat & \\
\hline 0 & 0 & 0.00 & 100.00 & 100.00 \\
\hline 12 & 12 & 0.72 & 99.28 & 99.34 \\
\hline 195 & 207 & 12.45 & 87.55 & 87.76 \\
\hline 563 & 770 & 46.33 & 53.67 & 53.98 \\
\hline 717 & 1487 & 89.47 & 10.53 & 10.92 \\
\hline 122 & 1609 & 96.81 & 3.19 & 3.49 \\
\hline 11 & 1620 & 97.47 & 2.53 & 2.86 \\
\hline 40 & 1660 & 99.88 & 0.12 & 0.15 \\
\hline 2 & 1662 & 100.00 & 0.00 & 0.00 \\
\hline & ata-rata Mod & ulus Kehalusa & & 3,42 \\
\hline
\end{tabular}

b. Pengujian Kadar Air Agregat Halus

\begin{tabular}{|l|c|c|c|}
\hline \multirow{2}{*}{ Pengujian } & \multirow{2}{*}{ Notasi } & \multicolumn{2}{|c|}{ Sampel } \\
\cline { 3 - 4 } & & I & II \\
\hline Berat Nampan & W1 & 60 & 60 \\
\hline $\begin{array}{l}\text { Berat Nampan + Benda Uji } \\
\text { Basah }\end{array}$ & W2 & 460 & 460 \\
\hline $\begin{array}{l}\text { Berat Nampan + Benda Uji } \\
\text { Kering }\end{array}$ & W3 & 451 & 450 \\
\hline Berat Air & W4 =W2-W3 & 9 & 10 \\
\hline
\end{tabular}




\begin{tabular}{|l|c|c|c|}
\hline Berat Uji kering & $\begin{array}{c}\text { W5 }=\text { W3 }- \\
\text { W1 }\end{array}$ & 391 & 390 \\
\hline Kadar Air & W4/W5 x 100 & 2,30 & 2,56 \\
\hline Kadar Air Rata-rata & \multicolumn{2}{|c|}{2,43} \\
\hline
\end{tabular}

C. Pengujian Berat Isi Agregat Halus

\begin{tabular}{|l|c|c|c|}
\hline \multirow{2}{*}{\multicolumn{1}{|c|}{ Lepas / Gembur }} & Nota & \multicolumn{2}{c|}{ Sampel } \\
\cline { 3 - 4 } & si & I & II \\
\hline Berat Tempat + Benda Uji & $\mathrm{A}$ & 6.875 & 6.855 \\
\hline Berat Tepat & $\mathrm{B}$ & 2.370 & 2.370 \\
\hline Berat Benda Uji & $\mathrm{C}$ & 4.505 & 4.485 \\
\hline Volume Tempat & $\mathrm{D}$ & 3.141 & 3.141 \\
\hline Berat Isi Benda Uji & $\mathrm{C} / \mathrm{D}$ & 1,43 & 1,42 \\
\hline Berat Isi Rata-rata & \multicolumn{3}{|c|}{1,43} \\
\hline
\end{tabular}

\begin{tabular}{|l|c|c|c|}
\hline \multirow{2}{*}{ Padat } & Nota & \multicolumn{2}{c|}{ Sampel } \\
\cline { 3 - 4 } & si & I & II \\
\hline Berat Tempat + Benda Uji & $\mathrm{A}$ & 6.910 & 6.875 \\
\hline Berat Tepat & $\mathrm{B}$ & 2.370 & 2.370 \\
\hline Berat Benda Uji & $\mathrm{C}$ & 4.540 & 4.505 \\
\hline Volume Tempat & $\mathrm{D}$ & 3.141 & 3.141 \\
\hline Berat Isi Benda Uji & $\mathrm{C} / \mathrm{D}$ & 1,44 & 1,43 \\
\hline Berat Isi Rata-rata & \multicolumn{3}{|c|}{} \\
\hline
\end{tabular}

\section{d. Pengujian Berat jenis Agregat Halus}

\begin{tabular}{|l|c|c|c|}
\hline \multicolumn{1}{|c|}{ Pengujian } & \multirow{2}{*}{ Notasi } & \multicolumn{2}{|c|}{ Sampel } \\
\cline { 3 - 4 } $\begin{array}{l}\text { Berat Benda Uji Jenuh Kering } \\
\text { Permukaan (SSD) }\end{array}$ & $\mathrm{S}$ & 500 & 500 \\
\hline Berat Benda Uji Kering Oven & $\mathrm{A}$ & 705 & 704 \\
\hline Berat Piknometer + Berisi Air & $\mathrm{B}$ & 1005 & 1004 \\
\hline $\begin{array}{l}\text { Berat Piknometer + Benda Uji + } \\
\text { Air Sampai Batas Pembacaan }\end{array}$ & $\mathrm{C}$ & 490 & 490 \\
\hline
\end{tabular}

\begin{tabular}{|l|c|c|c|c|}
\hline \multicolumn{1}{|c|}{ Perhitungan } & \multirow{2}{*}{ Notasi } & \multicolumn{2}{|c|}{ Sampel } & $\begin{array}{c}\text { Rata- } \\
\text { rata }\end{array}$ \\
\cline { 3 - 4 } & I & II & \\
\hline $\begin{array}{l}\text { Berat Benda Uji Curah } \\
\text { Kering (Sd) }\end{array}$ & $\frac{\mathrm{A}}{\mathrm{B}+\mathrm{S}-\mathrm{C}}$ & 2.45 & 2.45 & 2.45 \\
\hline $\begin{array}{l}\text { Berat Benda Uji Jenuh } \\
\text { Kering Permukaan (S) }\end{array}$ & $\frac{\mathrm{S}}{\mathrm{B}+\mathrm{S}-\mathrm{C}}$ & 2.50 & 2.50 & 2.50 \\
\hline Berat Jenis Semu (Sa) & $\frac{\mathrm{A}}{\mathrm{B}+\mathrm{A}-\mathrm{C}}$ & 2.58 & 2.58 & 2.58 \\
\hline Penyerapan Air (Sw) & $\frac{\mathrm{S}-\mathrm{A}}{\mathrm{A}} \times 100 \%$ & 2.04 & 2.04 & 2.04 \\
\hline
\end{tabular}

e. Pengujian Kadar Zat Organik Agregat Halus

\begin{tabular}{|l|c|c|}
\hline \multicolumn{1}{|c|}{ Pengujian } & Sampel & Sampel \\
\cline { 2 - 3 } & I & II \\
\hline $\begin{array}{l}\text { Benda Uji Kering Oven dalam Botol } \\
500 \mathrm{ml}\end{array}$ & 130 & 130 \\
\hline $\begin{array}{l}\text { Benda Uji + Larutan Natrium Sulfat } \\
\text { (Na OH) }\end{array}$ & 200 & 200 \\
\hline Standar colour chart & No. 3 & No. 3 \\
\hline
\end{tabular}

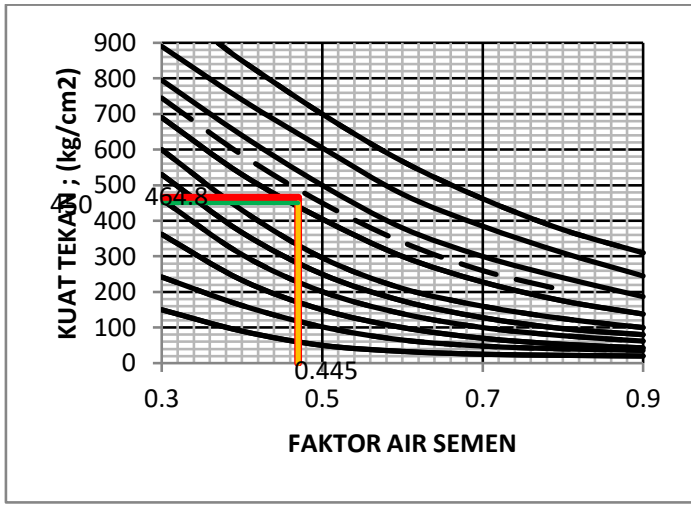

Gambar 1 Hasil Grafik Hubungan Antara Kuat Tekan dan Faktor Air Semen (Benda Uji Berbentuk Kubus $150 \times 150 \times 150 \mathrm{~mm}$ )

Sumber: Hasil Pengujian Labor

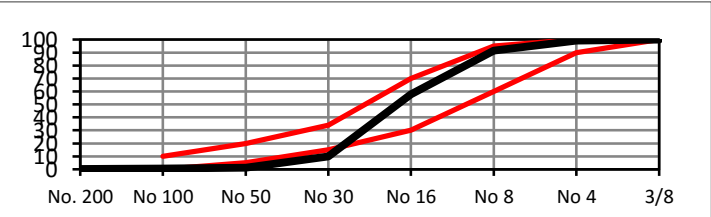

Gambar 2 Hasil Grafik Batas Gradasi Pasir (Kasar) Sumber: Hasil Pengujian Labor

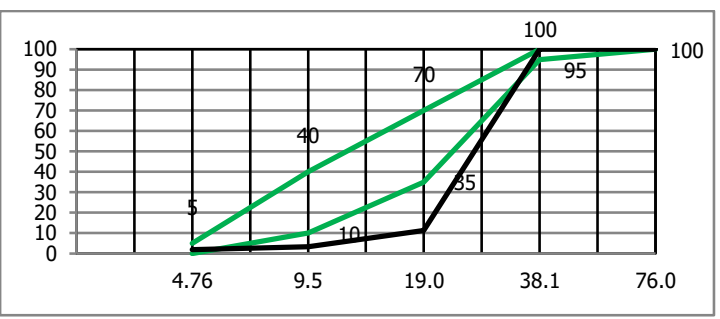

Gambar 3 Hasil Grafik Batas Gradasi Batu Pecah Ukuran Maksimum 40

Sumber: Hasil Pengujian Labor

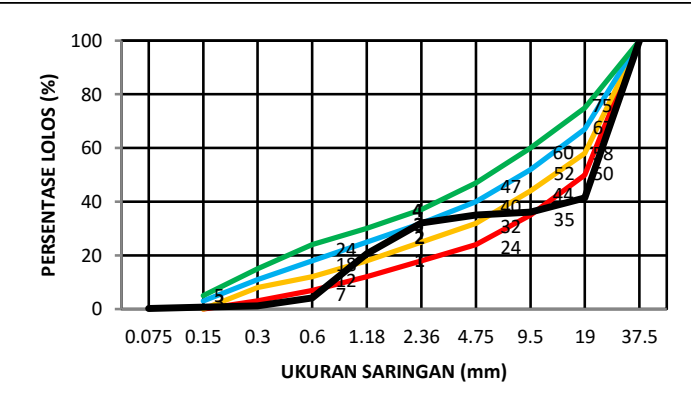

Gambar 4 Hasil Batas Gradasi Agregat Gabungan untuk Besar Butir Mak (40mm) Sumber: Hasil Pengujian Labor

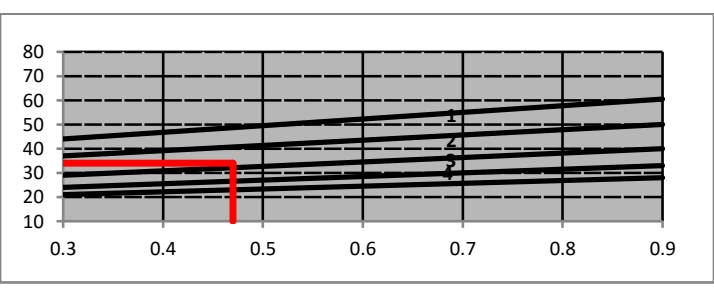

Gambar 5 Hasil Grafik Persentase Agregat Halus terhadap Agregat Keseluruhan Slump 60 - 180 mm (Untuk Ukuran Butir Maksimum 40 mm) Sumber: Hasil Pengujian Labor

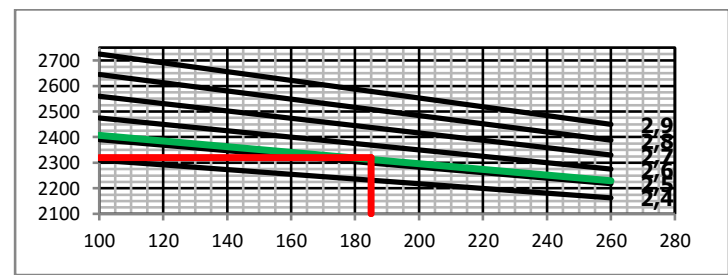

Gambar 6 Hasil Grafik Perkiraan Berat Jenis Beton Basah dimampatkan Penuh

\subsection{Pembahasan}

Penelitian yang dilakukan ternyata dengan air kolam pun mampu menghasilkan beton mutu tinggi, asal betul-betul memperhatikan bahan campuran beton, perbandingan komposisi material adukan 
beton, tata cara pembuatan rencana campuran beton dan perawatan beton (curing). Pembuatan JMF (Job Mix Formula) menggunakan air suling (air galon My Qua) mendapatkan hasil kuat tekan rata-rata untuk umur 28 hari $=528 \mathrm{~kg} / \mathrm{cm} 2$, dengan JMF yang sama penggunaan air kolam Kecamatan Kateman untuk kuat tekan ratarata untuk umur 28 hari $=491 \mathrm{~kg} / \mathrm{cm} 2$, Kecamatan Keritang kuat tekan rata-rata untuk umur 28 hari $=469 \mathrm{~kg} / \mathrm{cm} 2$ dan Kecamatan Tembilahan Kota kuat tekan ratarata untuk umur 28 hari $=475 \mathrm{~kg} / \mathrm{cm} 2$. Kuat

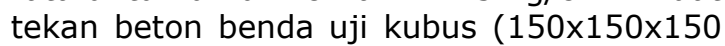
$\mathrm{mm}$ ) semuannya masuk sesuai perencanaan K350 yang direncanakan.

\section{KESIMPULAN}

\subsection{Kesimpulan}

Berdasarkan hasil penelitian dan pembahasan, maka dapat ditarik kesimpulan untuk kuat tekan beton rata-rata umur 3, 7 dan 28 hari sebagai berikut.

\begin{tabular}{|c|c|c|c|c|}
\hline \multirow{2}{*}{ No } & \multirow{2}{*}{ Sumber Air } & \multicolumn{3}{|c|}{ Umur Beton } \\
\cline { 3 - 5 } & & 3 Hari & 7 Hari & 28 Hari \\
\hline 1 & Kec. Kateman & $684 \mathrm{~kg} / \mathrm{cm}^{2}$ & $549 \mathrm{~kg} / \mathrm{cm}^{2}$ & $491 \mathrm{~kg} / \mathrm{cm}^{2}$ \\
\hline 2 & Kec. Keritang & $612 \mathrm{~kg} / \mathrm{cm}^{2}$ & $545 \mathrm{~kg} / \mathrm{cm}^{2}$ & $469 \mathrm{~kg} / \mathrm{cm}^{2}$ \\
\hline 3 & $\begin{array}{c}\text { Kec. Tembilahan } \\
\text { Kota }\end{array}$ & $652 \mathrm{~kg} / \mathrm{cm}^{2}$ & $552 \mathrm{~kg} / \mathrm{cm}^{2}$ & $475 \mathrm{~kg} / \mathrm{cm}^{2}$ \\
\hline
\end{tabular}

1. Air tidak layak minum tanpa kandungan zat organik, senyawa-senyawa berbahaya yang tercemar garam, minyak dan gula, mampu menghasilkan Beton Mutu Tinggi.

2. Metode kerja pembuatan beton mempengaruhi hasil kuat tekan yang direncanakan.

\section{DAFTAR PUSTAKA}

[1] Departemen Pekerjaan Umum 2000. Metode Pengujian Kuat Tekan Beton Silinder dengan Cetakan Silinder di dalamTempat Cetakan dengan Standar SK SNI 03-6429-2000. Badan Standarisasi Nasional.

[2] Departemen Pekerjaan Umum 2004. Semen Portland Komposit dengan Standar SK SNI 157064-2004. Badan Standarisasi Nasional.

[3] Tjaronge, M Wihardi. Teknologi Bahan Lanjut, Semen dan Beton Berongga. Makassar: CV. Telaga Zamzam. 2012.

[4] Tjokrodimulyo, Kardiyono (2007). Teknologi Beton. Yogyakarta: teknik Sipil dan Lingkungan Universitas Gadjah mada.

[5] Nugraha, Paul \& Antoni. (2007). Teknologi Beton dari Material, Pembuatan, ke Beton Kinerja Tinggi. Yogyakarta: Andi.

[6] PBI NI-2 (1971). Peraturan Beton Bertulang Indonesia. Bandung: Direktorat Penyelidikan
Masalah Bangunan, Departmen Pekerjaan Umum dan Tenaga Listrik.

[7] PERMEN No.3/PRT/M/2011. Pedoman Tata Cara Pelaksanaan Penggunaan Semen Tanah Sebagai Komponen Utama Bangunan Sabo. Kementrian Pekerjaan Umum.

[8] Setiawan, Agus (2016). Perancangan struktur Beton Bertulang Berdasarkan SNI 2847:2013 . Jakarta: Erlangga.

[9] Mulyono, Tri. Teknologi Beton. Yogyakarta: Andi. 2003.

[10] Nugraha, Paul dan Antoni. 2007. Teknologi Beton. Yogyakarta: Andi.

[11] SNI 03-1968-1990. Metode Pengujian Analisis Saringan Agregat Kasar dan Halus. Badan Standardisasi Nasional BSN.

[12] SNI 2417-2008. Cara Uji Keausan Agregat dengan Mesin Abrasi Los Angeles. Badan Standardisasi Nasional BSN.

[13] SNI 03-1986-1990. Metode Pengujian Tentang Analisa Saringan Agregat Halus dan Kasar. Pusjatan, Balitbang, Departmen Pekerjaan Umum.

[14] SNI-03-1972-1990. Metode Pengujian Slump Beton. Pusjatan, Balitbang, Departmen Pekerjaan Umum.

[15] SNI 03-1974-1990. Metode Pengujian Kuat Tekan Beton. Pusjatan, Balitbang, Departmen Pekerjaan Umum.

[16] SNI-03-2834-1993. Tata Cara Pembuatan Rencana Campuran Beton Normal. Pusjatan, Balitbang, Departmen Pekerjaan Umum.

[17] SNI 03-2847-2002. Tata Cara Perhitungan Struktur Beton untuk Bangunan Gedung Dilengkapi Penjelasan. Surabaya: itsprees.

[18] SNI 03-2834-1990. Tata Cara Pembuatan Rencana Campuran Beton Normal. Badan Standardisasi Nasional BSN.

[19] SNI 03-2834-2000. Tata Cara Pembuatan Rencana Campuran Beton Normal. Badan Standardisasi Nasional BSN.

[20] SNI 1969_2008. SNI 1969_2008. Berat Jenis Agregat Kasar. Badan Standardisasi Nasional BSN.

[21] SNI 2493_2011. Tata Cara Pembuatan dan Perawatan Benda Uji di Laboratorium.

[22] SNI 1969_2008. Berat Jenis Agregat Kasar. Badan Standardisasi Nasional BSN.

[23] SNI 1970_2008. Berat Jenis Agregat Halus. Badan Standardisasi Nasional BSN.

[24] SNI 6369_2008. Buat Keping Beton Silinder. Badan Standardisasi Nasional BSN.

[25] SNI 1974_2011. Uji Kuat Tekan Beton Silinder. Badan Standardisasi Nasional BSN.

[26] SNI-03-1974-1990 Metode Pengujian Kuat Tekan Beton.

[27] SNI-15-7064-2004 Semen Portland Composite. 